\title{
Loess Tourism Resource Exploitation Strategy in the Chinese Loess Plateau: A Case Study of White Deer Plateau
}

\author{
Hongmei Dong \\ School of Management, Xi' an University of Science and Technology \\ Xi'an 710054, China \\ College of Tourism and Environmental Sciences, Shaanxi Normal University \\ Xi' an 710062, China \\ E-mail: donghm_xian@163.com \\ Jingbo Zhao \\ College of Tourism and Environmental Sciences, Shaanxi Normal University \\ Xi' an 710062, China \\ Yougui Song \\ State Key Laboratory of Loess and Quaternary Geology, Institute of Earth Environment \\ Chinese Academy of Sciences, Xi'an 710075, China
}

\begin{abstract}
The research is financed by the Nature Science Foundation of China (No. 40672108, 40772116) and the National Basic Research Program of China (No: 2010CB833406) and the Fund of State Key Loess and Quaternary Geology (No: SKLLQG0605\&LQ 0701). (Sponsoring information)
\end{abstract}

\begin{abstract}
As one of the important geologic tourism resources in the world, the Chinese loess landscape tourism has not been developed deeply enough, which can not fulfill tourists' tourism demands on different levels. Based on many successful development experiences about sand tourism and ice snow tourism, according to the feature of loess environment, geographic conditions and traffic advantage, combining the advantages, features and development actuality of the loess landscape on the Chinese Loess Plateau, the idea of constructing the loess sculpture garden on the White Deer Plateau is proposed in the article. The main problems existing in the tourism development of the White Deer Plateau are analyzed, and the necessity and feasibility to construct the loess sculpture garden are demonstrated, and the main contents to establish the loess sculpture garden in the White Deer Plateau are proposed. The loess sculpture garden can completely show the special natural landscapes and the humanistic landscapes in the Loess Plateau, enhance the landscape value of the loess landscapes, deeply dig the scientific and educational values, closely combining the landscape feature with the popular science oriented feature, drive the development of the tourism of the White Deer Plateau and make it to become the hot landscape and the popular science base of the tourism.
\end{abstract}

Keywords: Chinese Loess Plateau, White Deer Plateau, Tourism exploitation, Loess sculpture garden, Leisure and knowledge, Popular science bases

\section{Introduction}

As the important landscape in the nature, the loess geomorphic landscape in Chinese Loess Plateau has been concerned widely by the geosciences circles (Guo, 2008, P.107-124 \& Xu, 2004, P.1871-1882 \& B. Fu, 1994, P.33-40), but as a kind of tourism resource, the loess landscape is ignored up to now (Wu, 2005, P.513-519 \& Zhao, 2007, P.95-99). The loess geomorphic landscape includes not only the loess stratum section which is the best Quaternary continental record in the world, but the erosion landscape that the soils are eroded most seriously in the world, and specific loess wonders such as loess tableland ('Yuan' in chinese), loess ridge (Liang), loess hills (Mao) (Liu T S, 1985, P.1-251), rivers and 
gorges, which largely attract domestic and foreign tourists. The White Deer Plateau (here Plateau is named as Yuan in local Chinese, a tableland landform) is the largest plateau near Xi' an city, and its exposed loess stratum completely and systematically records the past environment change (Bloemendal J, 2008, P.152-168 \& Zhao J, 2008, P.665-676), which possesses higher scientific and research values, and is the important resource to study the geology and develop the popular science tourism. Because the tourism development emphases of the White Deer Plateau are only limited in the Hundreds Hectares Cheery Garden and the Cetacean Channel at present, so the development of the special and abundant loess tourism resources is still ignored, which not only wastes the resources, but limits the tourism development space of the White Deer Plateau. Therefore, it is very important to strengthen the development of the loess tourism resources in the White Deer Plateau.

According to the feature of loess environment, geographic conditions and traffic advantage, combining the advantages, features and development actuality of the loess landscape on the Loess Plateau, combining with tourists' intensive requirements for the participation, knowledge and culture of the tourism products, the idea of constructing the loess sculpture garden on the White Deer Plateau is proposed in the article. The visual, lively and abundant loess physiognomy landscape, the loess and environment, and the loess culture full of Chinese characters will be utilized to drive the development of the tourism industry in the White Deer Plateau, promote the advance of the loess culture and create the new mode of geological popular science tourism. And the White Deer Plateau will be constructed as the Chinese loess geological popular science tourism base and the "large tourism plateau" in the area of Xi'an.

\section{Geographic situation of the White Deer Plateau}

The White Deer Plateau is located to the southeast of Xi'an City, the southwest of Lishan Mountain, and the northwest of Shaoling Plateau. It lies between the Chanhe River and the Bahe River, and the its length is about 28km, and its width is about $7 \sim 10 \mathrm{~km}$ with a area $238 \mathrm{~km}^{2}$, and it is the largest loess plateau near Xi' an City. The Cetacean Channel transverses the plateau, and the northern part is called as Dizhai Plateau, and the souther is called as Paoli Plateau. The altitude of the plateau ranges from $650 \mathrm{~m}$ to $780 \mathrm{~m}$ a.s.1 with the highest $803.9 \mathrm{~m}$. The surface of the plateau rises northeast, and descends southwest, and the height differences between the northern plateau and the Bahe River are in 260 350m, and the height differences between the southern plateau and the Chanhe River are in 150 200m. The gullies and streams in the White Deer Plateau mainly include Gaojiagou gully, Shenyusi gully, Wanggou gully and Cetacean stream. The lengths of former three gullies are about $5 \mathrm{~km}$, but the length of the Cetacean stream is about $25 \mathrm{~km}$.

The tourism resources of the White Deer Plateau are abundant and diversiform, and they include the loess plateau and ravine physiognomy landscape, the graceful water landscapes such as reservoirs, springs and gullies, the woodlands and agricultural landscapes, the literature tourism resource of "White Deer Plain", the deep historical and cultural tourism resource, the famous Hanwen Baling Mausoleum, Quen Mother Bo Mausoleum, Queen Dou Mausoleum, site of Diqing Camp, the live custom culture resource, and the cave-house sites where villagers lived in early years such as Changchungou gullyl and Sunjiagou gully. But at present, only the Hundreds Hectares Cheery Garden and the Cetacean Channel are developed, and most tourism resources are still in the state of un-development or the state of waiting development, so the development potential of the tourism is very large.

\section{Problems existing in the tourism development in the White Deer Plateau}

\subsection{The tourism development lacks in characters and the issues are not obvious}

At present, the tourist activities in the White Deer Plateau mainly include the cherry sightseeing and picking tour and the cetacean channel reservoir sightseeing tour. Though the former is popular in recent years and it is the special tourism item which is different with the strawberry sightseeing and picking tour, the grape sightseeing and picking tour, and the guava sightseeing and picking tour around $\mathrm{Xi}$ 'an, but its character of season is obvious and the duration is too short, and it can not present the topic tourism issues in the White Deer Plateau. The latter is largely identical but with minor differences with the valley and water landscape tour in the north of Qinling Mountain, and it can not compare with the market attraction and admittance of the valley and water landscape tour resource in the north of Qinling Mountain. The tourism development of the White Deer Plateau has not formed its own characters and attractions, so without obvious topic issues, there is not the development space of the tourism market.

\subsection{The tourism product is single and the market scale is small}

The tourism development of the White Deer Plateau still emphasizes traditional tourism resources such as valley, water and agriculture, and the market supply only includes sightseeing tourism products on the lower layer which are mainly to fulfill citizen's tourism demands in Xi'an, but ignore the developments of the resources such as the loess landscape, the folk-custom of the White Deer Plateau which are more interesting for middle and long-distance tourists, so the structure of the tourism product is single, and it can not fulfill the market demand of the tourists on the high layer.

\section{The necessity to construct the loess sculpture garden on the White Deer Plateau}

\subsection{The scientific knowledge of loess can be comprehensively and systematically popularized}

The popular science tourism is the necessity of the deep development in future tourism zones, and the demand to 
implement the national quality education. The loess landscape in the White Deer Plateau is the important carrier to develop the science education tourism which can attract foreign and domestic experts and geology fans to review and explore, and the loess sculpture garden established in the White Deer Plateau can comprehensively present the physiognomy landscape in the Loess Plateau, the loess and ice age, the paleosol and interglacial stage, vegetation, sand storm, ground water, the loess cultural landscapes to attract common tourists who can really see the Loess Plateau and systematically know the loess science knowledge. In addition, the national quality will be enhanced in deed.

\subsection{The loess landscapes on the Loess Plateau can be showed newly and visually}

It is not rare to construct the tourism landscapes by the sculptures, for example, the ice sculpture (Dewar K, 2001, P.523-532) and the sand sculpture have been mature and typical mode to develop and utilize the ice resource and the sand landscape in many tourism areas, but it is new development mode to sculpture typical loess natural and humanistic landscapes of the Loess Plateau by the loess. For this mode, the topic is brighter, the connotation is more abundant, and the expression is more special, and it can enhance the tourism value of the loess landscape and attract more people's concerns. On the other hand, to really know the loess landscapes, it is not enough to only appreciate it on the spot, especially for those large-scale physiognomy landscapes such as loess tableland, loess ridge, loess hills, channel, and the physiognomy of Yellow River, tourists only see the locals of these landscapes, but in fact, it will more experience the vast vigor of the Loess Plateau to see the panorama than to only see the locals. At present, by virtue of fire balloon, helicopter and other tools, few tourists can realize that, but for the mass, the economic and feasible method is to sculpture these physiognomy landscapes and let tourists easily to realize this target.

\subsection{The tourism landscape in the White Deer Plateau can be enriched}

The loess sculpture garden can form special tourism attractions. Furthermore, it can be combined with many landscapes such as mountain, water, forest, farmland and cultures to form tourism products with different layers and types. When tourists study the science knowledge about loess, they can make man with clays, carve by loess, experience real earth cave-house, enjoy the picking interests in the gardens around the landscapes, and swim in the water scenery area, which can not only leave tourists, but drumbeat the tourism issue of the White Deer Plateau.

\subsection{The social and economic development of the White Deer Plateau can be driven}

As the important part of Xi'an, the White Deer Plateau will influence the total development level and the regional harmony of Xi'an in the economic development. But the White Deer Plateau is still the area giving priority to the agricultural production and management, and the industrial development lacks in resources and bases. Though the tourism industry has abundant resources, but the scale effect of the development can not be formed at present, and the local residents have few employment opportunities, and the social and economic development is relatively lagged. Therefore, the development, construction and management of the "loess sculpture garden" will offer more employment opportunities for local residents, and improve the social and economic development of the White Deer Plateau.

\section{Advantages and characters to construct the loess sculpture garden}

The advantages and characters to construct the loess sculpture grader are very obvious as follows.

\subsection{Unique loess plateau in the world}

The Chinese loess plateau is unique in the world, and it is located from the north Yinshan Mountain to the south Qinling Mountain and from the west Riyueshan Mountain to the east Taihang Shan, traversing the territories of Qinghai, Ningxia, Gansu, Shannxi, Shanxi and Henan. It covers an area of approximately $640,000 \mathrm{~km}^{2}$. The depth of the loess sediments is in $100 \mathrm{~m} \sim 200 \mathrm{~m}$, and the deepest depth is above $500 \mathrm{~m}$, located in the Jingyuan of Gansu Province. The types of the loess physiognomy are diversiform, and the landscapes are beautiful, and the loess stratum grows completely, and it is the unique physiognomy landscape area in the arid and semi-arid region of the world.

\subsection{The largest loess physiognomy in the world}

The physiognomy forms of the Loess Plateau are diversiform, and the ravines on the ground are located vertically and horizontally, which is called by the "fragmented landform". There is the largest loess plateau, Dongzhi Plateau, in the world, and its longest length from north to south is $110 \mathrm{~km}$, and its longest length from east to west is $50 \mathrm{~km}$, and its area is about $910 \mathrm{~km}^{2}$. And there is the most typical loess plateau in the world, Luochuan Yuan, and it not only has large-scale physiognomies such as loess tableland, loess ridge, loess hills and streams, but small-scale physiognomies such as loess coast, loess landslip, loess suspended gullies, loess water-falling cavities, loess bridges, loess poles and loess walls which possess special sculptures and appreciation values. Luochuan Plateau also has clear loess sections, continuous and complete stratum, clean age-old soil layer and higher learning value, and it has been developed as the national geological park. There is the White Deer Plateau which is concerned by global literature fans. And there is the second largest rive in the Loess Plateau, the Yellow River, which cuts the loess plateau and helps to form the special river physiognomy landscapes including the gorges and curving flows. The Yellow River has about ninety nine bending flows, 
and the most beautiful one is the Jinshan Gorge which generates the world-famous Hukou Waterfall. The loess physiognomy landscape is the most core part of the loess tourism.

\subsection{Specific humanistic landscape in the loess plateau}

The special natural environment of the Loess Plateau gestated special loess cave dwellings, typical agricultural terrace landscapes, full-bodied dietary culture and dress culture, wedding custom, funeral custom, abundant traditional arts and cultures such as civil arts and crafts, civil dances and songs, civil musical instruments, civil music and civil amusement, and these multiform and original humanistic landscapes are special in the Loess Plateau, and tourists can experience different lives in different regions in the Loess Plateau, so these landscapes possess specific tourism attractions.

\section{Feasibility to construct the loess sculpture garden}

\subsection{The loess wonder is famous in the world, and it has large attraction}

There is the world-famous Loess Plateau in China, and the loess physiognomy landscapes here have the largest-scale one in the world, and the most complete loess stratum section landscape which grows best in the world, and the corrosion landscapes where the soil is corroded worst in the world, which can largely attract domestic and foreign tourists, and are the resource base to construct the loess sculpture garden. The White Deer Plateau belongs to the loess plateau with deep soil stratum of above $100 \mathrm{~m}$, so there are abundant material bases to construct the loess sculpture garden. The loess sculpture is the important part in Chinese ancient sculptures, and the soil sculpture located in the Shanglan Village of Taiyuan is the ancient rare soil sculpture production in China, but most of these ancient soil sculptures were made by original soil, and the soil quality is loose and easy to be eroded by rains and they are difficult to be conserved. But the red clay in the White Deer Plateau is very striking, and because these soils contain more clay, so their rigidity is higher, and they can bear more pressures, and the laterites can be used to sculpture. Comparing with the manufacturing techniques of sand sculptures and ice sculptures, not only these soils are easy to be sculptured, but the sculptures created by them can be conserved longer, and the relative construction costs are lower.

\subsection{The traffic is very convenient}

Convenient traffic is the necessary condition for most successful tourism items. The White Deer Plateau is located in the southeast Xi'an City, connecting with round-city highways, Hu-shan highway, Lian-huo highway and Xi'an-Yanliang highway, which can be linked with the roads arriving to the Plateau, and there are many public lines such as Route 406 in Xi'an connecting with the White Deer Plateau, and the drive time to the White Deer Plateau is only 30 minutes.

\subsection{It is near with the world historical and cultural city, Xi'an, and the passenger flux is large}

Another necessary condition of the successful tourism item is the selection of the position which decides the passenger source. Though Luochuan Loess Plateau has strong attractions for exterior provincial tourists, but the loess sculpture garden should not be constructed in Luochuan but in the White Deer Plateau because of the passenger source market. The White Deer Plateau abuts against Xi'an City, and it is the important space to develop the tourism for Xi'an. Xi'an is the historical and cultural city with reputation in the whole world, and it was the capital of 13 dynasties in the history, and it has been the world-famous tourism city. On the other hand, in thousands years' development of the historical and cultural city, Xi'an has been a comprehensive metropolis, and it possesses dense population, high economic development level and strong resident consumption ability, and it is one of main tourism consumption cities in China. Numerous local tourists and many foreign tourists will be the target market of the White Deer Plateau Loess Sculpture Garden.

\subsection{The demand of the science and technology tourism is more and more intensive}

As a special tourism activity on higher layer, the science and technology is increasingly favored by people. At present, Chinese public have higher concerned degree to the science and technology knowledge, especially for the selections about the science and technology resources such as the biology, geography and astronomy (Liu, 2008, P.34-39). Therefore, the White Deer Plateau should grasp the opportunity, fully utilize many research result of the loess, establish the loess sculpture garden, fully develop the loess popular science tourism and fulfill people's demands and desires.

\subsection{The White Deer Plateau has good reputation}

The reputation has been the key factor to influence the tourism item marketing. If one region has good and high reputation, tourists will more easily accept and believe in the tourism drumbeating and promotion. The saga novel, "White Deer Plateau" wrote by the modern famous writer, Chen Zhongshi, made this silent land to be well known by the world, which has established firm base for the marketing of the loess sculpture garden tourism.

\section{Main contents to construct the loess sculptures on the White Deer Plateau}

The construction of the White Deer Plateau loess sculpture garden must be implemented under the concept of the sustainable tourism development, taking the features of science, culture, location and characteristic as the principles. 
The garden including the Loess Garden, the loess physiognomy landscape, the loess stratum, and humanistic loess landscape and the loess amusement should be the popular science topic garden with specific topic, multiform types and abundant contents.

\subsection{Sculpturing the landscapes of the Loess Plateau}

To make domestic and foreign tourists comprehensively perceive the Loess Plateau, the Loess Plateau must the sculptured first. First, the remote sensing image of the Loess Plateau can be used to instruct the concrete sculpture design, and clearly depict the landform characters such as loess tableland, loess ridge, loess hills, river, channel and mountains to present the total landscape formation of the Loess Plateau. Second, the scientific knowledge of the Loess Plateau should be transferred to passengers, and the knowledge include the source and formation of the loess, the basic character and utilization values of the loess, the forming reason, range, area and environmental character of the Loess Plateau. Of course, many technical measures such as 3D cartoon, visual reality technology and traditional color picture with lively scientific explanation can be adopted to enhance the newness sense and the amusement feature.

\subsection{Sculpturing the landscapes of the loess physiognomy}

In the loess physiognomy landscapes, the typical and representative physiognomy landscapes with large area and higher reputation, well combining with other loess landscapes should be selected to sculpture. First, Dongzhi Plateau, Luochuan Plateau and White Deer Plateau should be sculptured, and the there are above 2000 ravines at the sides of the Dongzhi Plateau to run out the hinterland of the Dongzhi Plateau, and the ravine which is nearest with the plateau is only 50 with the heart of the plateau, which can make tourists know not only the characters and changes of the Dongzhi Yuan, but the serious influences of human activities to the water and soil losses in the Loess Plateau to enhance their environment-protective consciousness. The loess tableland, loess ridge, loess hills and channels in the Luochuan Plateau grew well, and the small-scale physiognomy landscapes are complete, so the sculpture could help tourists form a clear understanding for the complete growth process of the loess physiognomy landscapes. The White Deer Plateau is the largest loess plateau near Xi'an, and the historical plateau and the cultural plateau, and one of important reasons is that the novel of "White Deer Plateau" pushed it to the world. Finally, the Yellow River and its special river physiognomy landscapes should be sculptured to show the forming process of the river physiognomy. The sculptures of the loess physiognomy can show not only various large-scale physiognomies, but small-scale physiognomies landscapes, and the target is to let tourists know the types, characters, causes, growth process of the loess physiognomy, and form a complete and scientific cognition to the forming and changing process of the Loess Plateau.

\subsection{Sculpturing the section of the loess stratum}

The important meaning to sculpture the loess section is to make tourists know the scientific knowledge about the loess and the past environment change. First, the typical loess-paleosoil sequence of the Loess Plateau should be sculptured, and its core intention is to transfer the ancient climate change, soil, vegetation, sand storm, groundwater and other geological environment information since the Fourth Age reflected by the different stratums in the loess section to tourists, and the key is to set up the stratum marks and corresponding explanation words. Of course, because the White Deer Plateau also has disclosed loess sections with continual, complete, clear and well-conserved stratum, so 2 or 3 spots in the Plateau can be selected to show, and make tourists to have the sensitive cognitions to the relationship between the loess and the environment. Tourists can observe, look, touch and feel these landscapes, and combining with easy and facetious language explanations, they will acquire a clear and comprehensive understanding to the relationship between the loess and the environment.

\subsection{Sculpturing the humanistic landscape of the Loess Plateau}

The humanistic landscape sculptures in the Loess Plateau include three parts, i.e. the loess carve-house, the sloping terrace and the folk-customs. Because the loess folk-custom landscapes are lively landscapes which have strong participation feature and experience feature, and the sculptured folk-custom landscapes have not these advantages, so when the loess folk-custom is shown, the loess cave-house yards can be taken as the background, the people's real livings in different regions of the Loess Plateau can be taken as the references, and the loess folk-custom scenes with certain characters can be constructed to show the civil arts and crafts, traditional dietary cooking, civil songs and dances and civil music, and protect, dig and inherit the traditional cultures of the Loess Plateau. According to the story of the saga novel "White Deer Plateau", the farming, grinding stone, fowl breeding, daily customs, amusement, traditional Shehuo and other life scenes can be recovered and developed, and some typical story scenarios can be sculptured to fulfill human demands for the "White Deer Plateau".

Finally, to enhance the tourism interests of the loess sculpture garden, the design of the amusement item is the necessary part of the garden construction. But because the items of the loess amusement are less, so the water and rural tourism resources should be integrated and developed. Tourists can not only make man and sculptures with clay, but participate in the water amusement items such as yacht surfing, yacht sightseeing, fishing, swimming and handle boat, and the farming activities such as picking. 


\section{Conclusions}

First, the loess physiognomy in the Chinese Loess plateau has large tourism value, and it is not only the excellent site to implement the geological research, but the important resource to develop the popular science tourism. At present, the tourism development of the White Deer Plateau is still in the initial stage, and the tourism products are single, and the characters are not prominent, and the topic image is not concrete, so it is necessary to construct the loess sculpture garden. The sculptures can not present the micro physiognomy landscape, but show macro physiognomy model, which offer effective approach to appreciate vast loess physiognomy landscapes. The loess sculpture garden can drive the large development of the Xi'an White Deer Plateau tourism industry, and more important, it can create a new mode of the geological popular science tourism.

Second, it has obvious resource advantage and characters to construct the loess sculpture garden, which can completely and systematically popularize the scientific knowledge about loess, and visually show the loess landscapes of the Loess Plateau. The White Deer Plateau is near the Xi'an City, and convenient traffic and entrances, large passenger flux and high reputation are all advantageous and necessary conditions to construct the loess sculpture garden.

Third, the loess sculpture garden will sculpture the largest loess plateau in the world and the largest loess plateau in Shannxi, the Yellow river and other large-scale river physiognomies, the soil erosion and erosion landscapes to show the largest loess physiognomy landscapes in the world; and sculpture loess stratum section landscapes grew best in the world and the specific humanistic landscapes of the Loess Plateau in the Loess Plateau to enhance the appreciation values of the loess landscapes, deeply dig its scientific and educational values, combine the appreciation feature with the popular science-based feature, and make it become the hotspot of the tourism and the based of the popular science education.

\section{References}

B. Fu, H. Gulinck. (1994). Land evaluation in an area of severe erosion: The loess plateau of china. Land Degradation and Development, No. 5 (1). P. 33-40.

Bloemendal, J, Liu, X M, Sun, Y B, et al. (2008). An assessment of magnetic and geochemical indicators of weathering and pedogenesis at two contrasting sites on the Chinese Loess plateau. Palaeogeography Palaeoclimatology Palaeoecology, No. 257(1-2). P. 152-168.

Botti, L, Peypoch, N \& Solonandrasana, B. (2008). Time and tourism attraction. Tourism Management, No. 29(3). P. 594-596.

Dewar, K, Meyer, D, Li, W M. (2001). Harbin, lanterns of ice, sculptures of snow. Tourism Management, No. 22(5). P. 523-532.

Guo, An T, Fayuan L I. (2008). Landform Classification of the Loess Plateau Based on Slope Spectrum from Grid DEMs. Advances in Digital Terrain Analysis, P. 107-124.

Liu, Jun, Cheng, Shengkui \& Chen, Yuansheng et al. (2008). Study on Tourists' Perception of Hi-tech Tourism Resources in Park and Zone Category: A Case of Olympic Games Village Hi-tech Park, Chinese Academy of Sciences. Tourism Tribune, No. 23(7). P. 34-39.

Liu, T S. (1985). Loess and the Environment. Beijing: China Ocean Press. P. 1-251.

Wu, Chengji, Tao, Yingke \& Lin, Mingtai et al. (2005). Discussion on the Utilization of Landform Scenery Resources of Loess Plateau in Northern of Shannxi. Journal of Mountain Science, No. 23(5). P. 513-519.

$\mathrm{Xu}, \mathrm{J}$. (2004). Temporal variation of river flow renew-ability in the middle Yellow River and the influencing factors. Hydrological Processes, No. 19(9). P. 1871-1882.

Zhao, J, Gu, J, Du, J. (2008). Climate and soil moisture environment during development of the fifth palaeosol in Guanzhong Plain. Science in China (D-Earth Sciences), No. 51(5). P. 665-676.

Zhao, Ting, Lu, Zi \& Wu, Chengji. (2007). The Probe about the Aesthetics Value of Shaanxi Loess Plateau Landforms Landscape. Journal of Shanxi Normal University (Natural Science Edition), No. 21(3). P. 95-99. 